\title{
Obstacles to Research and Publication in Zimbabwean Higher Education Institutions: A Case Study of the Research and Intellectual Expo
}

\author{
EVELYN CHIYEVO Garwe (Corresponding author) \\ Zimbabwe Council for Higher Education \\ Zimbabwe \\ E-mail: garweec@gmail.com
}

Received: January 26, 2015

Accepted: February 10, 2015 Published: March 13, 2015

doi:10.5296/ire.v3i1.7009

URL: http://dx.doi.org/10.5296/ire.v3i1.7009

\begin{abstract}
The study was aimed at exploring the quantum and quality of research in higher education institutions (HEIs) in light of the stringent requirements for staff appointment, tenure and promotion. The case study method which falls within the qualitative research paradigm was employed. Documentary analysis was used to determine the trends in the number of articles submitted to the Research and Intellectual Expo (RIE) and those that are eventually published in the Journal of Zimbabwe studies from 2011 to 2014. In addition, interviews with 111 respondents ( 25 peer reviewers, 11 members of the Journal's editorial staff, 45 academics, 10 Research Directors and 20 members of the organising Committee) were performed for purposes of obtaining explanations and justifications for the trends obtained from the case study. Results indicate that although the number of articles submitted to the RIE had increased over the years (from 218 in 2011 to 498 in 2014), there are serious deficiencies in research and writing skills among academics in HEIs. However, variations in publication rates exist depending on academic field with those in the science-related disciplines producing better quality research articles than those in education, arts, humanities and social sciences. The major reasons for rejection of papers were poor research and writing skills as well as plagiarism. New forms of academic dishonesty namely: 'ghost' researches and unjustified multiple authorship were unearthed. The major challenge faced by the academics in conducting research was the pressure to publish in an environment characterised by high teaching loads and inadequate resources. The paper recommends collaboration by key stakeholders in imparting research and academic writing skills to and academics.
\end{abstract}


Keywords: research, publication, higher education institutions, staff promotion

\section{Introduction}

\subsection{Background}

A baseline survey by performed in 2010 by the Ministry of Higher and Tertiary Education and the United Nations Education and Scientific and Cultural Organisation (UNESCO) revealed that the status of research in higher education institutions in Zimbabwe had declined significantly terms of quantity, quality, thrusts, and contribution to national development. This decline in research and scholarly activities was attributed a number of reasons as detailed in the Baseline survey report (Ministry of Higher and Tertiary Education (2010). The major reason emanated from the serious brain drain that led to the exodus of qualified and experienced staff in higher education institutions (HEIs). Universities were forced to replace these with staff who were not adequately qualified and had limited experience in lecturing and research. In addition to the effects of brain drain, research activities were also adversely affected by limited access to internet, poorly resourced libraries, shortage of equipment, non-functional publishing outlets like local journals, inadequate funding, lack of fuel as well as disturbances and temporary closure of universities.

\subsection{The Problem}

The current situation regarding the status of research in higher education institutions in Zimbabwe has not been documented. A few studies have indicated that quality research is still lacking in these institutions due to lack of exposure to research and publication, too high workloads caused by too much focus on teaching at the expense of research, inadequate funding and few local journals and other publication outlets (Majoni, 2014). This position is buttressed by Bukaliya and Muyengwa, (2012) who reported that, in response to the call for promotions to senior lectureship and professorship by the Zimbabwe Open University (ZOU), only 3 out of the 26 lecturing staff in Mashonaland East managed to submit their applications. However, their study does not indicate whether or not these applications were successful. Gonye, Mareva, Dudu and Sibanda (2012) decry the poor academic writing skills of university students in Zimbabwe, indicating that their essays and assignments are riddled with a plethora of flaws. Unfortunately, the study fails to link the poor quality of work by university students to the calibre and capabilities of their lecturers. Presumably, the poor research and writing skills of the lecturers could be responsible for this state of affairs. The current study provides empirical evidence on the research and writing skills of staff from higher education institutions in Zimbabwe.

\subsection{The Importance of Research and Publication in Higher Education Institutions}

The importance of scholarly research and publication in HEIs in Zimbabwe has been accentuated by the rationilisation of recruitment, tenure and promotion criteria for universities by the Zimbabwe Council for Higher Education (ZIMCHE), a national body which superintends over quality assurance (ZIMCHE, 2013). Prior to the implementation of the rationalised promotion structure each of the 15 registered universities had its own criteria enshrined in their respective ordinances. ZIMCHE, the government and higher education 
institutions work together in enforcing these minimum standards that guide recruitment, tenure and promotion of all academic staff in Zimbabwe. ZIMCHE performs annual audits to make sure that institutions are complying. On the other hand, the government through the Ministry of Higher and Tertiary Education, Science and Technology Development and the Ministry of Finance and Economic Planning make sure that they increase salaries for only the academics who are promoted using the ZIMCHE benchmarks. Most institutions have engaged Research Directors to assist in the promotion of research within their institutions.

The requirement of quality and quantum of scholarly research for engagement and upward career mobility of academics is not peculiar to Zimbabwe, Berendt (1981), Mwamwenda (1994) and Jimoh (1995) reported that promotion of academic staff depends on a sound record of research publications in Berlin, Ghana and Nigeria, respectively. Research, creation of knowledge, scholarship and innovation important pillars universities the world over (Bentley \& Blackburn, 1991; Hearn, 1999; Mutula, 2006). Research and scholarship activities contribute to the pool of literature and enhance the reputation, recognition and credibility of both the academic and the HEI (Plucker, 1988; Tien \& Blackburn, 1996). Publication and dissemination of research is important for the transfer and adaptation, of knowledge and innovations across the world. HEIs are expected to guarantee the most efficient creation, dissemination and utilisation of research results and their possible application to economic life. The most common method used as a barometer to assess the value of an academic in this arena is to evaluate the quantity and quality of their research output in the form of tangible scholarly publications, artefacts and patents (Cozzetto, 1994; Houston \& Delevan, 1994; Forrester, 1996; Kellough \& Pitts, 2005; Kraemer \& Perry, 1989; Rodgers \& Rodgers, 2000); Stallings \& Ferris, 1988; Wright, Manigault, \& Black, 2004).

It is sad to note that whilst research is a critical component of responsibilities for academics in higher education institutions, researchers have found that universities in the developing world have very poor research outputs (Sanyal \& Varghese, 2006; Ministry of Higher and Tertiary Education, 2010). By way of attempting to bridge that gap, starting from 2011, the Ministry of Higher and Tertiary Education, Science and Technology Development has been promoting research in Zimbabwe though the Research and Intellectual Expo (RIE). RIE provides a platform for Zimbabwean scholars from higher and tertiary institutions to showcase their academic outputs and innovations through presentation of their research papers and exhibition of artefacts, patents and other scholarly and artistic works. RIE welcomes free access and participation by all institutions of higher learning, secondary schools, research organisations, industry and commerce, government officials, politicians and the general public. The papers that are presented at RIE undergo a thorough peer review process and selected papers are published in two Journals namely: Journal of Zimbabwe Studies: Arts, Humanities and Education and Journal of Zimbabwe Studies: Science, Technology and Health.

\section{Appointment, Promotion and Tenure of Academic Staff}

Researchers are in agreement that all over the world, scholarly works and publications appearing in recognised professional platforms are used as the primary productivity measure 
for academic staff engagement, promotion and tenure (Braskamp \& Ory, 1994; Lazear, 1998; Pellino, Boberg, Blackburn, \& O’Connell, 1981; Wong \& Tierney, 2001). Academics often see a conflict between these reward and appraisal systems and their own values and efforts (Colbeck, 1994; Plucker, 1988; Serow, 2000). They cite various factors that hinder them achieving these expectations. Lack of institutional and external support in terms of providing funding for research activities is the key among the reasons (Hardré, et al., 2007; Kiriuki, 2000; Oyowole, 2009; Serow \& Demry; 1999; Zeleza \& Olukoshi, 2004). The absence of time for research is another limitation since more time is usually devoted to teaching due to the high teaching loads and the need to moonlight in order to supplement meagre salaries (Buchheit et al., 2001; Chow \& Harrison, 1998; Colbeck, 2002; Hardré, Miller, Beasley, Pace, Maxwell, \& Xie,, 2007). In support of this assertion, several researchers have found a negative correlation between research output and teaching load (Bucheit, Collins, \& Collins, 2001; Chen, Gupta, \& Hoshower, 2006; Hardré et al., 2007; Hattie \& Marsh, 1996).

Various forms of stress have a negative impact on research activities and research output. For example studies have shown that anxiety arising from: poor salaries and conditions of service; professional ability and recognition, time constraints, and student interactions negatively affect research output both in terms of quality and quantity (Gmelch, Wilke, \& Lovrich, 1986).

The consistency with which institutions communicate their standards and expectations shapes was reported as having a huge impact on values and motivations and achievements of academic staff regarding the balance between research and teaching (Alpert, 1985; Baldwin \& Blackburn, 1981; Boice, 1992).

Personal issues, such as gender; family commitments; life and career stages; interest and attitude as well as self-motivation and incentives, influence research productivity (Bailey, 1999; Blackburn \& Lawrence, 1995; Jackson, 2004; Lee \& Rhoads, 2004; Levin \& Stephan, 1989; Sax, Hagedorn, Arredondo, \& Dicrisi, 2002).

\section{Scholarly Research in Zimbabwean Higher Education Institutions}

A baseline survey by performed by the Ministry of Higher and Tertiary Education and the United Nations Education and Scientific and Cultural Organisation (UNESCO) revealed that the status of research in higher education institutions in Zimbabwe had declined significantly terms of quantity, quality, thrusts, and contribution to national development (Ministry of Higher and Tertiary Education, 2010). This decline in research and scholarly activities was attributed a number of reasons including brain drain, poorly resourced libraries, limited access to internet, inadequate research equipment, unavailability of transport to visit research sites, limited journal and other publication outlets as well as absence of external research funding.

\subsection{Brain Drain}

A large number of experienced and well qualified academic staff left Zimbabwe between 2001 and 2008 due to economic problems (World University News, 2010). The Lecturers who were hired to replace them were either Bachelor degree holders or Master degree holders who were inexperienced in the rigours of research and could not generate enough meaningful research. 
The term "brain drain" refers to the movement of high-level experts from their native country or their organisation to other nations or jurisdictions as a result of various reasons including conflict, financial issues, lack of opportunity or health hazards (Odhiambo, 2004). The problem of undeveloped research skills in junior academic staff has been discussed in detail by other studies. For example, Biermann and Jordaan, (2007) in their study of research skills in universities in South Africa, discovered that academics at graduate level lacked research skills, leading to low research output. Mutula (2009) and Zakri (2006) recommend capacity building of researchers as a way to promote research in higher education institutions.

\subsection{Poorly Resourced Libraries and Limited Access to Internet}

Most university libraries were inadequately resourced and did not have current and diverse reading materials. The challenge was further exacerbated by the limited internet access due to low bandwidth, connectivity problems and frequent power cuts that negatively impacted on research activities. This state of affairs was also reported by Gakio (2006) who found internet access and connectivity in African higher education institutions to be 'too limited and too costly, furthermore, the institutions lacked expertise to manage it.

\subsection{Research Equipment and Transport to Research Sites}

Scientific research requires use of appropriate equipment and consumables. The existing equipment in higher education institutions was found to be non-functional, obsolete or unavailable. Transport to visit research sites was also a problem. This forced some researchers to abandon their research projects. This was mainly caused by the economic crisis that resulted in fuel shortage and a general unavailability of funds. Similar challenges affecting funding and resources for research were reported in other African countries (Kiriuki, 2000; Zeleza \& Olukoshi, 2004; Oyewole, 2009). Oyewole (2009) argues that considering the financial challenges faced by African governments and the concomitant reduction in funding public HEIs, funding for research is not considered as a priority. Manyika and Szanton (2001) whilst agreeing that research activities in African higher education institutions are inhibited by limited resources, attribute this state of affairs mostly to bureaucracy in the funding approval by the institutional research boards.

\subsection{Journals and Other Publication Outlets}

Academics also faced challenges in publishing their work. Manuscripts that were submitted to local journals and other scholarly publishers were not published due to financial, resource and other capacity challenges faced by publishers. Since it is expensive to publish in international journals, scholars found themselves demotivated to continue their research activities.

\subsection{External Research Funding}

Academics were experiencing challenges of external research funding as a result of the flight of traditional funding agents who were no longer willing to entrust their money to institutions after some research funds could not be accessed from the Central Bank during the economic crisis in Zimbabwe. 
All the foregoing impediments to research reported in the Ministry of Higher and Tertiary Education (2010) report were also registered by Mutula (2006) who found that most African countries, face challenges of brain drain, lack of adequate funding, poor research environment in terms of infrastructure and facilities, absence of research incentives, limited time available for research due to heavy teaching loads as well as poor research skills and inexperienced faculty.

\section{Objectives}

Following a dearth of information on the prevailing status of research in higher education institutions after the 2010 baseline survey, and in light of the stringent requirements for staff appointment, tenure and promotion, the was study aimed at investigating the quality of research and writing skills of staff from higher education institutions as well as assessing the challenges thereof.

\section{Methodology}

The study used the qualitative research paradigm which included a case study and interviews. A case study of RIE was used to explore the trends in articles submitted, those accepted for presentation and those subsequently in published in the Journal of Zimbabwe studies. The data covered a period of four years from 2011 to 2014. The case study was premised on document analysis of RIE Organising Committee (RIEOC) minutes, circulars and conference reports and analysis of statistics on papers submitted, accepted for presentation and those published for each of the four years. In addition to the case study, face to face interviews with 111 respondents were done to obtain explanations and justifications of the trends obtained from the case study. The interviews also provided detailed information on how RIE was organised. Interviewees were purposively selected according to their importance in managing the research and publication process. The interviewees were made up of 25 peer reviewers, 11 members of the editorial staff of the Journal, 45 academics, 10 Research Directors and 20 members of RIEOC. The 20 members of RIEOC that were interviewed included five from the Main Committee, the three from the Programme Design Committee, five from the Publications Committee, two from the Adjudication Committee, two from the Protocol Committee and three from the Finance Committee.

The interviewees were randomly selected from predetermined groups of people who play an important role in carrying out research as well as those involved in RIE, review and publication of the Journal. The face to face interviews used semi-structured interview guides and were designed to last for no more than 30 minutes. The questions included in each guide differed since they were specifically earmarked for each respective category of interviewees. For example, questions for academics and Research Directors generally sought to obtain more information on the research activities and challenges faced in higher education institutions whilst those targeted at peer reviewers and editorial staff dwelt on the reasons and why papers were rejected among other issues. All the 111 interviewees were very open and resourceful. 


\section{Results}

\subsection{Background, Scope and Information on the Research and Intellectual Expo}

The promotion of research involved a combination of efforts from the government, ZIMCHE, HEIs as well as industry and commerce. One of the initiatives, the Research and Intellectual Expo (RIE) was initiated by the Ministry of Higher and Tertiary Education, Science and Technology Development in 2009. ZIMCHE was given the mandate to organise RIE on an annual basis with the help of a RIE Organising Committee comprised of experts representing various sectors and areas of expertise. The aim was to provide a platform for showcasing to Zimbabweans, the research outputs and innovations produced by scholars in HEIs. As one of its mandates, RIE (under the copyright of ZIMCHE) publishes two Journals namely: Journal of Zimbabwe Studies: Arts, Humanities and Education and Journal of Zimbabwe Studies: Science, Technology and Health.

Starting from 2011 RIEOC invites scholars and researchers to submit abstracts for consideration for presentation at the Expo. The abstracts are then given to peer reviewers for vetting. The authors of the abstracts that are selected are invited to submit full papers that they will then present at the Expo. All the presented full papers are first submitted to anti-plagiarism software and then submitted to a thorough peer review process leading to publication of those that meet the quality standards.

Each year a different theme is used to embrace the prevailing and critical national imperatives. For every theme, seven sub-themes are maintained and these reflect all the academic disciplines taught in higher education institutions in Zimbabwe. These are: Education; Religion, Spirituality, Arts and Culture; Humanities and Social Sciences; Management, Leadership and Governance; Agriculture, Environment and Natural Resources; Science, Engineering and Technology and Health and Well-being. However, for the 2011 inaugural Expo, the sub-theme on Management, Leadership and Governance was not included in the call for papers. RIEOC had assumed that since the issues in this sub-theme cut across the other six sub-themes, academics in this area would still submit papers. Unfortunately no papers were submitted on management, leadership and governance issues in 2011 prompting RIEOC to add this sub-theme in the subsequent call for papers.

The themes for 2011, 2012, 2013 and 2014 were: Research and intellectual excellence: past present and future; Research, innovation and creativity for sustainable development; Research partnerships for wealth creation and Engagement, innovation and diversity for national transformation and development, respectively. The Expo for 2013 was not held due to circumstances beyond RIEOC's control. Consequently the papers for RIE 2013 were all presented at RIE 2014 which had its own separate theme and papers. The combined papers were peer reviewed at the same time. RIE consists of a conference segment, exhibitions as well as performing and visual arts. The official opening session highlights a distinguished lecture by world renowned academics and professionals including the Presidium. This is followed by keynote presentations by speakers of repute from any country in the world irrespective of their nationality. Participants include all the 15 universities; 12 polytechnics and industrial development centres; 14 teachers colleges, 22 research institutions, individuals 
and professional bodies. Members of the public, high schools and all the residents of Zimbabwe attend RIE.

\subsection{Trends in Articles Submitted, Presented and Published}

Table 1 shows the number of papers that were submitted, accepted for presentation at RIE 2011 and those that were eventually published as well as the publication rate.

Table 1. Number of submitted, presented and published papers and publication rate (2011)

\begin{tabular}{lcccc}
\hline Sub-theme & Submitted & Presented & Published & Publication Rate (\%) \\
\hline Education & 59 & 14 & 3 & 5.1 \\
Religion, Spirituality, Arts \& Culture & 18 & 7 & 3 & 16.7 \\
Humanities \& Social Sciences & 65 & 28 & 1 & 1.5 \\
Management, Leadership \& Governance & 0 & 0 & 0 & 0 \\
Agriculture, Environment \& Natural Resources & 47 & 23 & 4 & 8.5 \\
Science, Engineering \& Technology & 21 & 19 & 6 & 28.6 \\
Health and well-being & 13 & 9 & 3 & 23.1 \\
\hline Total/Average & $\mathbf{2 1 8}$ & $\mathbf{1 0 0}$ & $\mathbf{2 0}$ & $\mathbf{9 . 2}$
\end{tabular}

Table 1 show that the total number of papers submitted for RIE 2013 was 218. Out of these 100 were selected for presentation at the Expo. Nine percent of the originally submitted papers were found suitable for publication. As explained before there were no papers submitted for the Management, Leadership and Governance sub-theme. The publication rate ranged from 1.5-28.6\% depending on the sub-theme. Science, Engineering and Technology registered the highest publication rate (28.6\%), closely followed by Health (23.1\%).

The second edition of RIE held in 2012 showed an increase in the number of papers submitted (refer to Table 2) as well as the overall publication rate.

Table 2. Number of submitted, presented and published papers and publication rate (2012)

\begin{tabular}{lcccc}
\hline Sub-theme & Submitted & Presented & Published & Publication Rate (\%) \\
\hline Education & 70 & 33 & 2 & 2.9 \\
Religion, Spirituality, Arts \& Culture & 18 & 8 & 3 & 16.7 \\
Humanities \& Social Sciences & 97 & 37 & 8 & 8.2 \\
Management, Leadership \& Governance & 11 & 2 & 0 & 0 \\
Agriculture, Environment \& Natural Resources & 34 & 27 & 6 & 17.6 \\
Science, Engineering \& Technology & 30 & 24 & 8 & 26.7 \\
Health \& well-being & 21 & 17 & 1 & 4.8 \\
\hline Total & $\mathbf{2 8 1}$ & $\mathbf{1 4 8}$ & $\mathbf{2 8}$ & $\mathbf{1 0}$ \\
\hline
\end{tabular}

Table 2 shows that out of the 281 papers submitted to RIE 2012, 148 were presented and 28 were eventually published. The overall publication rate was $10 \%$. Interviews revealed that although 17 papers from the health and well-being sub-theme were presented at RIE, 10 of 
them had won prizes at the Medical Expo 2012 and had already been published elsewhere. However, it was imperative that such award winning researches be presented to the whole academic fraternity. The publication rate reflected here did not take this into consideration since only papers published in the Journal of Zimbabwe studies are reflected here.

Table 3. Papers submitted, presented and published and publication rate (2013/2014)

\begin{tabular}{lcccc}
\hline Sub-theme & Submitted & Presented & Published & Publication Rate (\%) \\
\hline Education & 149 & 69 & 3 & 2 \\
Religion, Spirituality, Arts \& Culture & 39 & 30 & 4 & 10.3 \\
Humanities \& Social Sciences & 138 & 77 & 3 & 2.2 \\
Management, Leadership \& Governance & 20 & 7 & 3 & 15 \\
Agriculture, Environment \& Natural Resources & 81 & 27 & 8 & 9.9 \\
Science, Engineering \& Technology & 43 & 41 & 11 & 25.6 \\
Health \& well-being & 28 & 16 & 6 & 21.4 \\
\hline Total & $\mathbf{4 9 8}$ & $\mathbf{2 6 7}$ & $\mathbf{3 8}$ & $\mathbf{7 . 6}$
\end{tabular}

Table 3 shows that out of the 498 papers submitted to RIE 2013/2014, 267 were presented and 38were selected for publication. The overall publication rate was $7.6 \%$. It is important to note that 2013/2014 was the first time for papers in Management, Leadership and Governance to be selected for publication.

Figure 1 illustrates the trends in the number of papers submitted and those that were published. There was an upward increase in the number of articles submitted over the three years. The number of papers increased from 218 in 2011 to 281 in 2012 and 498 in 2013/2014.

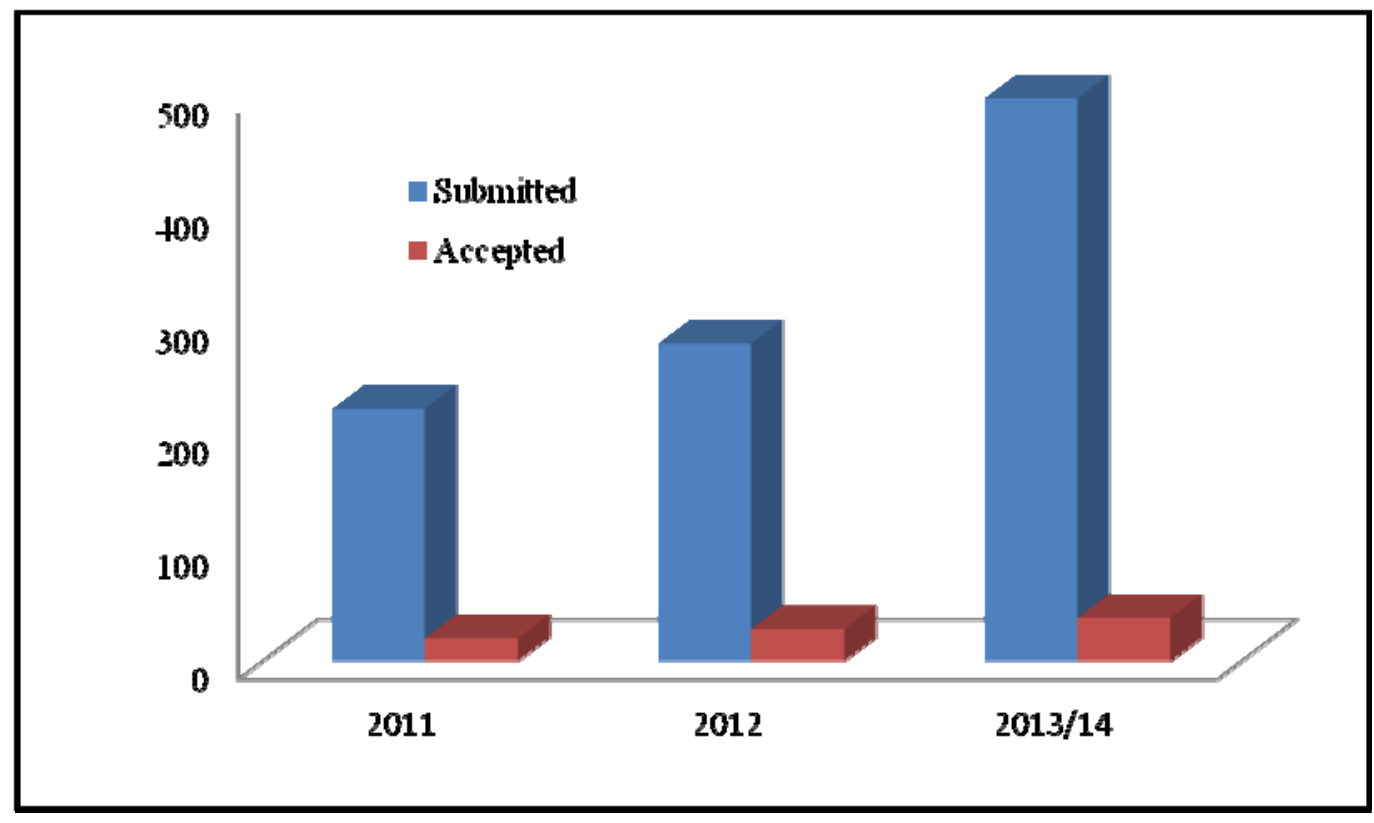

Figure 1. Trends in the number of articles submitted and those published 


\section{Macrothink}

International Research in Education

ISSN 2327-5499

2015, Vol. 3, No. 1

It can also be seen from Figure 1 that although there was an increase in the number of articles published over the study period, the increase was very small. The articles published in 2011, 2012 and 2013/2014 were 20, 28 and 38 respectively. Figure 2 shows the trend of the overall publication rate over the study period.

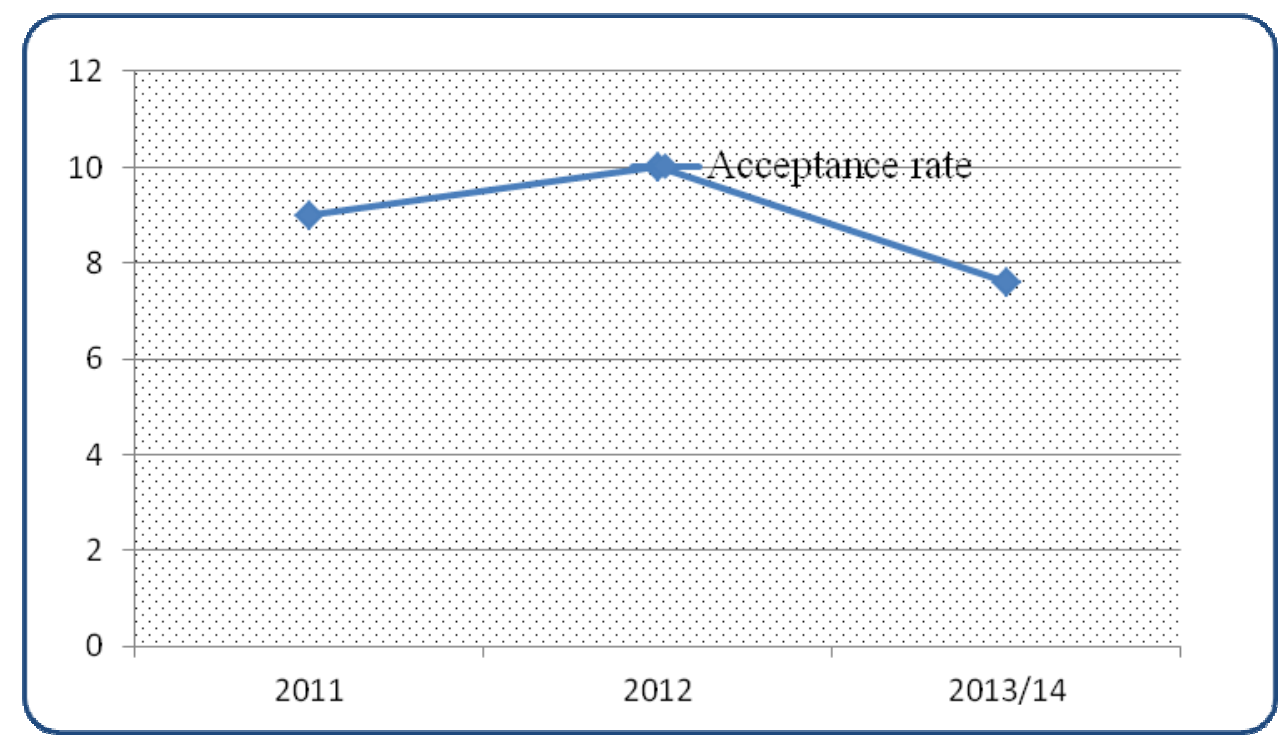

Figure 2. Trends in the overall publication rate from 2011 to 2014

Figure 2 shows that although there were slight changes in the publication rate, generally it did not change much over the study period. Figure 3 illustrates the trends in the publication rates for the different sub-themes.

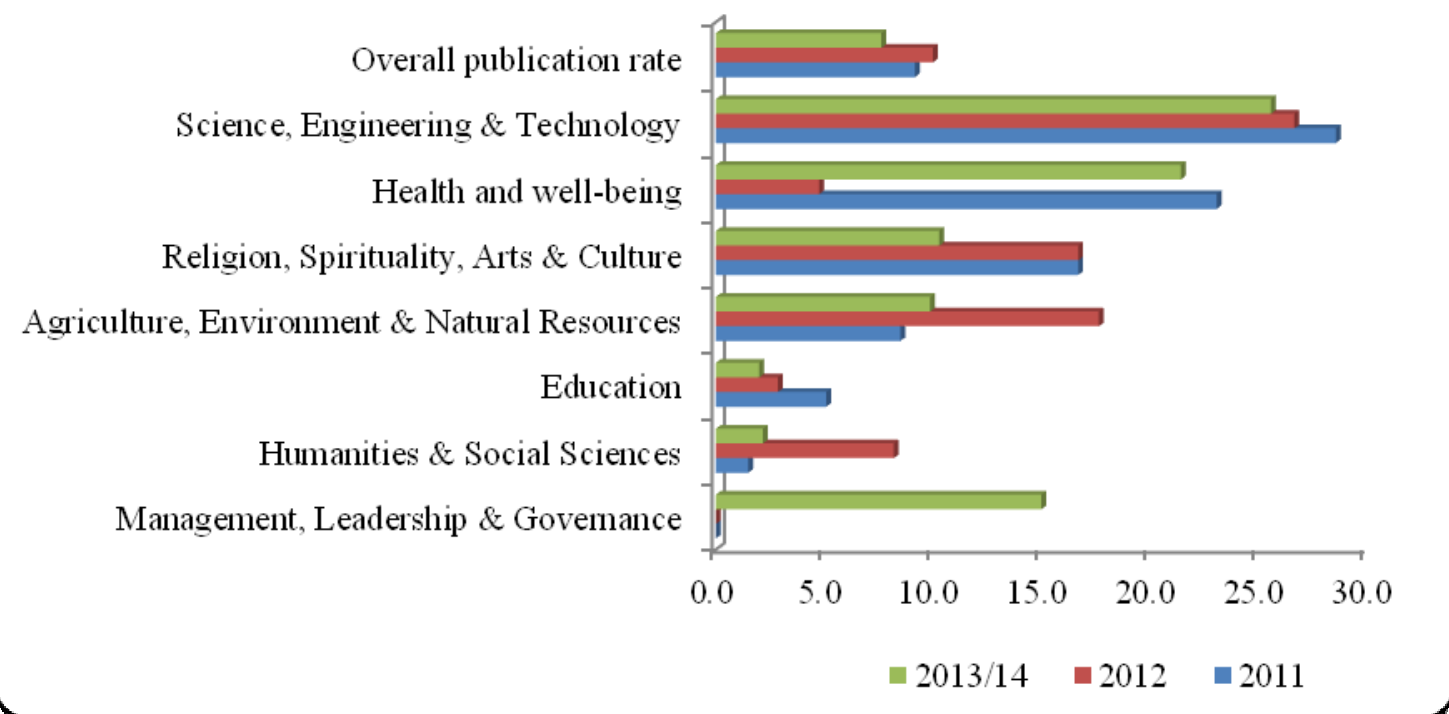

Figure 3. Trends in publication rates for the different sub-themes 
Figure 3 shows the trend in the acceptance rate for the years 2011, 2012 and 2013/2014. It can be seen that the publication rates for the science-related disciplines were higher than those in education, arts, humanities and social sciences.

\subsection{Findings from Interviews}

\subsubsection{RIE Organising Committee}

Interviews attributed the increase in articles submitted to the need for academics to satisfy the requirements for recruitment, tenure and promotion. Interviewees from the RIE Organising Committee narrated how they were inundated with requests from academics to indicate in writing that their papers were being considered for publication. This pressure to publish has been established to be a 'fact of life' in academia (Baruch \& Hall, 2004; Lucas, 2006; Smith, 1990). Publications advance knowledge frontiers and also influence individual career advancement (Bedeian et al., 2009) in terms of tenure and promotion (Glick et al., 2007). Career advancement results in job satisfaction, ego building and the attendant financial rewards as well as professional recognition (Bird, 2006).

\subsubsection{Peer Reviewers and Editorial Staff}

Peer Reviewers and editorial staff cited poor quality as the major reason for the rejection the papers for publication. The most critical elements that were assessed were originality, knowledge contribution to the discipline, technical quality, language clarity, presentation style, depth and impact of research. The major areas that resulted in poor research papers are listed below:

- high levels of plagiarism and evidence of fabrication and falsification of results

- poor stating of research topics in relation to the content of the paper and in relation to the theme

- failure to identify research gaps and research problems

- most papers were not research articles but just essays full of the author's opinions

- deficiencies in accurately describing the research methodology and issues to do with sampling and data collection tools and procedures. Questionnaire design was a problem with a good number of papers designing a questionnaire with only yes or no answers.

\subsubsection{Research Directors}

The Research Directors that were interviewed were of the opinion that these poor quality papers were as a result of the pressure on academics to publish even under unfavourable conditions. The high incidence of plagiarised papers was evidence enough to show that academics had to resort to academic dishonesty to fulfil their professional requirements. In studies elsewhere, Brice and Bligh (2004) also found that rampant author "misconduct' was attributed to the pressure to publish exerted on academics. Academics find no time to develop research, analytical and writing skills. This was particularly evident in this study were one Editor of the Journal of Zimbabwe Studies said; “The quality of papers that we received was 
outrageous to say the least. Most authors had no clue on how to write an abstract or a paper. They failed even to construct a coherent sentence in English and obviously they showed that they have not been schooled in the dictates of English grammar. In is inconceivable to imagine that these are indeed lecturers who are teaching our children!”

\subsubsection{Academics}

Interviews with academics revealed that they are trying their best to carry out research under very unfavourable conditions. They cited lack of institutional funds to carry out research as the major reason leading to poor quality of research. Academics have to fund research from their pockets and this presented challenges in proper research formulation and implementation. They admitted that many times they were forced to cut corners. One academic remarked, "In the past researchers were given funding to attend conferences to present their papers and benefit from the comments given. Nowadays conferences and seminar have become the preserve of University Management. Surprisingly the same people demand that academics should produce quality papers in order to guarantee promotion.” The facilities for carrying out research were either very poor or non-existent. This is consistent with the study by Maunde, (2003) who found research facilities in Zimbabwe to be among the poorest in Africa. Maunde (2003) estimated that it would take a period of time to instil a culture of reading, writing and research. This is quite a paradox considering that Zimbabwe is ranked the highest in Africa (92\%) in terms of literacy rate (Share, 2010).

Academics mentioned that the very high teaching loads (up to 35 hours a week) and the high enrolments (particularly in business, commerce, education, humanities and social science disciplines) made it impossible for them to concentrate on research. This state of affairs also made them unsuitable for entry into doctoral studies since admission also demanded that the candidate should have some good publications. This would in turn further jeopardise their chances of getting promoted. A certain lecture had this to say, "How can you expect me to qualify to be a doctoral candidate when they require publications? I teach Business Law to a class of 600 students. Although I have three Teaching Assistants to assist with marking and tutorials, I just do not have time to breathe let alone research or write a manuscript.” Maybe this explains why papers from the science-related fields tended to have high quality compared to the other disciplines.

The academics interviewed recommended that there was need to address the challenges cited in order to create the right environment, motivate and improve the quality of research outputs. This would need both external and institutional support systems to be implemented to provide training, mentoring, funding, provision of good infrastructure and equipment as well as exchange programmes for staff and student researchers.

\subsection{Challenges Faced in Research and Publication}

Editorial staff, Peer Reviewers and Directors of Research revealed worrying trends that had developed over the years. To begin with, there were instances were up to nine authors from the same academic discipline especially arts, social studies, humanities and education were now teaming up to share a single paper. Each co-author would concentrate on developing one 
paper and then just appending names of other colleagues to increase the overall gains in the quantum of publications. These academics were hiding behind the current prominence of collaborative research. However, their collaborations were not inter-displinary in nature; neither did they add any value. This pointed towards a new form of academic misconduct.

The other new trend was that some academics were now concentrating on the research areas and topics that needed a short time to accomplish. Others were using data collection methods that were easy and quick to perform and complete. The methodology employed by most articles was heavily dependent on use of questionnaires. These studies rarely made use of other data gathering techniques for example observations, interviews, and focus group discussions. The science, technology and health disciplines also made extensive use of the questionnaires and very few studies were lab-based or field based. Some Research Directors also mentioned that "it is not unusual to see a lecturer submitting articles to journals for researches that were never carried out - at least to our knowledge as colleagues. We refer to those kind of articles as 'ghost' research.” The reasons given for this were inadequate funding and resources. What is clearly evident is the pressure to publish for reasons of tenure and promotion. Other researchers found that the need to get promotion is the major motivator propelling academics to engage in research (Jimoh, 1995) and that the greater the pressure, the higher the tendency for academics to deviate from the norms of the profession (Anderson et al., 2007). It is critical to maintain academic integrity in research by accurately reporting findings, being open to criticism and correctly acknowledging sources of information.

\subsection{Discussion and Recommendations}

The study revealed an increase in the quantity of papers submitted by academics in higher education institutions to RIE. This was also confirmed through interviews with the RIE Organising Committee, Peer Reviewers and Research Directors. The quality of the papers remained poor largely because of plagiarism and poor research and writing skills by the academics. The problem of undeveloped research skills in academic staff in HEIs was also identified in South Africa in a study by Biermann and Jordaan (2007), in their study of research skills in universities in South Africa, discovered that academics at graduate level lacked research skills, leading to low research output. Mutula (2009) and Zakri (2006) recommend capacity building of researchers as a way to promote quality research in higher education institutions.

Academics blamed the poor quality of research on the pressure imposed on them to publish in order to be tenured or promoted. This was being done in an environment fraught with inadequate resources; high teaching loads and large classes. Similar challenges affecting research productivity in HEIs were reported in other African countries (Kiriuki, 2000; Zeleza \& Olukoshi, 2004; Oyewole, 2009). Oyewole (2009) argues that considering the financial challenges faced by African governments and the concomitant reduction in funding public HEIs, funding for research is not considered as a priority. Manyika and Szanton (2001) whilst agreeing that research activities in African HEIs are inhibited by limited resources, attribute this state of affairs mostly to bureaucracy in the funding approval by the institutional research boards. 
New trends in research relating to: unjustified multiple authorship, "ghost" researches and over-reliance on easy and fast data collection techniques to carry out research. Whilst multiple authorships are encouraged in inter-displinary and collaborative research, the tendency was to have up to nine academics from the same discipline who team up to produce one article each but they then put all their names in each and every article. This pointed towards a new form of academic misconduct! Lewis et al. (2012) criticised this erroneous measurement of research collaboration through co-authorship of papers arguing that collaboration should be used as a strategy for enriching research and not for maximising research output. Couture and Rymer (1991) made a distinction between collaborative authorship (writing collectively) and interactive writing (involving soliciting views and comments from others), to support their thesis that collaborative writing is rarely practiced. Historically, collaborative research was mostly common in science-based disciplines (Chen et al., 2013).

The study recommends joint efforts by the RIE Organising Committee, ZIMCHE and institutions to come up with writers' workshops and training sessions for budding researchers. The academics should also be trained on matters like plagiarism, research methods, how to conduct research, ethics in research and how to write quality articles. Academics need to be exposed to seminars and conferences where they either practise their presentation and writing skills or simply listen to presentations by experienced and renowned researchers and scholars. In addition the government, industry and other development partners need to provide adequate funding for research and development.

\section{Conclusions}

The present study showed an increase in papers submitted to RIE over the study period as a result of new career development benchmarks and a targeted research promotion drive. Unfortunately this increase resulted in an upsurge of research quantum and not quality. The study also highlighted the reasons for producing poor quality research as well as the challenges faced by the academics in conducting research. There is hope that given the correct environment academics can improve the quality of research outputs. There is therefore a need for both external and institutional support systems to be put in place to influence the research efforts of academics. This includes training, mentoring, funding, providing of good infrastructure and equipment as well as exchange programmes for staff and student researchers. HEIs, ZIMCHE and all stakeholders should join hands and find strategies to improve research and academic writing skills. This will in turn motivate and enhance opportunities for upward career movement of academics. Since academics publish articles in many journals, the limitation of the study was that it focused only on the articles that were submitted to the Journal of Zimbabwe studies. Future research should therefore focus on publications in totality.

\section{References}

Akomolafe, C. O. (2000). Utilization of previous and current research outcomes as a management tool for educational development. Nigeria Journal of Educational Research and Evaluation, 2, 1. 
Alpert, D. (1985). Performance and paralysis: The organizational context of the American research university. Journal of Higher Education, 56, 241-281. http://dx.doi.org/10.2307/1981734

Altbach, P., \& Lewis, L. (1997). The academic profession in international perspective In P. Altbach (Ed.), The international academic profession: Portraits of fourteen countries (pp. 3-48). Princeton, NJ: Carnegie Foundation for the Advancement of Teaching.

Bailey, J. G. (1999). Academics' motivation and self-efficacy for teaching and research. Higher Education Research and Development, 18(3), 343-359. http://dx.doi.org/10.1080/0729436990180305

Baldwin, R. G., \& Blackburn, R. T. (1981). The academic career as a developmental process. Journal of Higher Education, 52, 598-614. http://dx.doi.org/10.2307/1981769

Baruch, Y., \& Hall, D. T. (2004). The academic career: a model for future careers in other sectors? Journal of Vocational Behaviour, 64, 241-62. http://dx.doi.org/10.1016/j.jvb.2002.11.002

Bedeian, A. G., Van Fleet, D. D., \& Hyman, H. H. III. (2009). Scientific achievement and editorial-board membership. Organizational Research Methods, 12, 211-38. http://dx.doi.org/10.1177/1094428107309312

Bellas, M. L., \& Toutkoushian, R. T. (1999). Faculty time allocations and research productivity: Gender, race and family effects. Review of Higher Education, 22(4), 367-390. http://dx.doi.org/10.1353/rhe.1999.0014

Bentley, R. J., \& Blackburn, R. T. (1991). Changes in academic research performance over time: A study of institutional accumulated advantage. Research in Higher Education, 31(4), 327-353. http://dx.doi.org/10.1007/BF00992271

Berendt, B. (1981). Improving teaching and learning in higher education. International Conference Report, 28 September- 10 October.

Berlin (west) Bird, S. J. (2006). Research ethics, research integrity and the responsible conduct of research. Science and Engineering Ethics, 12, 411-112. http://dx.doi.org/10.1007/s11948-006-0040-9

Biermann, E., \& Jordaan, M. C. E. (2007). Developing Applied Research Skills in 4thYear Students Using E-learning: A Case Study. Paper Presented at the WWW Applications Conference Held from 5-7 September 2007 at the University of Johannesburg, South Africa.

Blackburn, R. T., \& Lawrence J. H. (1995). Faculty at work: Motivation, expectation, satisfaction. Baltimore, MD: The Johns Hopkins Press.

Boice, R. (1992). The new faculty member. San Francisco, CA: Jossey-Bass.

Braskamp, L. A., \& Ory, J. C. (1994). Assessing faculty work: Enhancing individual and institutional performance. San Francisco, CA: Jossey-Bass. 
Brice, J., \& Bligh, J. (2004). Author misconduct: Not just the editors' responsibility Medical Education, 39, 83-89.

Bucheit, S., Collins, A. B., \& Collins, D. L. (2001). Intra-institutional factors that influence accounting research productivity. Journal of Applied Business Research, 17(2), 17-32.

Bukaliya, R., \& Muyengwa, B. (2012). Challenges affecting faculty in research and publication works: a case of the Zimbabwe Open University. Asian Journal of Social Sciences and Humanities, 1(4), 139-149.

Chen, Y., Gupta, A., \& Hoshower, L. (2006). Factors that motivate business faculty to conduct research: An expectancy theory analysis. Journal of Education for Business, 81(4), 179-189. http://dx.doi.org/10.3200/JOEB.81.4.179-189

Cheng, M. Y., Hen, K. W., Tan, H. P., \& Fok, K. F. (2013). Patterns of co-authorship and research collaboration in Malaysia. Aslib Proceedings, 65(6), 659-674. http://dx.doi.org/10.1108/AP-12-2012-0094

Chow, C. W., \& Harrison, P. (1998). Factors contributing to success in research and publications: Insights of 'influential' accounting authors. Journal of Accounting Education, 163(4), 463-472. http://dx.doi.org/10.1016/S0748-5751(98)00030-X

Colbeck, C. (1992). Extrinsic rewards and intrinsic interest: The influence of tenure on faculty preference for teaching or research. Paper presented at the annual meeting of the Association for the Study of Higher Education, Minneapolis, MN.

Colbeck, C. (1994). The contexts of academic work: What matters to faculty. Paper presented at the annual meeting of the Association for the Study of Higher Education, Tucson, AZ.

Colbeck, C. (1997). The main reciprocal of teaching load: Faculty use of research time. Paper presented at the annual meeting of the American Educational Research Association, Chicago, IL.

Colbeck, C. (2002). Integration: Evaluating faculty work as a whole. New Directions for Institutional Research, 114, 43-52. http://dx.doi.org/10.1002/ir.45

Couture, B., \& Rymer, J. (1991). Discourse interaction between writer and supervisor: A primary collaboration in workplace writing. In M. M. Lay \& W. M. Karis (eds.): Collaborative Writing in Industry: Investigations in Theory and Practice (pp. 87-108). Amityville, NY: Baywood Publishing Company. http://dx.doi.org/10.2190/CWIC5

Cozzetto, D. A. (1994). Quantitative research in public administration: a need to address some serious methodological problems. Administration and Society, 26(3), 337-343. http://dx.doi.org/10.1177/009539979402600303

Gakio, K. (2006). African tertiary institutions connectivity surveys. ATICS Report.

Glick, W. H., Miller, C. C., \& Cardinal, L. B. (2007). Making a life in the field of organization science. Journal of Organizational Behaviour, 28, 817-35. http://dx.doi.org/10.1002/job.455 
Gmelch, W. H., Wilke, P. K., \& Lovrich, N. P. (1986). Dimensions of stress among university faculty: Factor-analytic results from a national study. Research in Higher Education, 24(3), 266-286. http://dx.doi.org/10.1007/BF00992075

Gonye, J., Mareva, R., Dudu, W. T., \& Sibanda, J. (2012). Academic writing challenges at Universities in Zimbabwe: A case study of great Zimbabwe University. Journal of English and literature, 3(3), 71-83.

Hardré, P. L., Miller, R. B., Beasley, A., Pace, T., Maxwell, M. S., \& Xie, K. (2007). What motivates university faculty members to do research? Tenure-track faculty in research-extensive universities. Journal of the Professoriate, 2(1), 75-99.

Hattie, J., \& Marsh, H. W. (1996). The relationship between research and teaching: Ameta-analysis. Review of Educational Research, 66, 507-542. http://dx.doi.org/10.3102/00346543066004507

Hearn, J. C. (1999). Faculty salary structure in research universities: Implications for productivity. In W. Tierney (Ed.), Faculty productivity: Facts, fictions and issues (pp. 123-173). New York, NY: Falmer Press.

Houston, D. J., \& Delevan, S. M. (1994). A Comparative Assessment of Public Administration Journal Publications. Administration and Society, 26(252), 252-271. http://dx.doi.org/10.1177/009539979402600207

Jackson, J. (2004). The story is not in the numbers: Academic socialization and diversifying the faculty. NWSA Journal, 16(1), 172-185. http://dx.doi.org/10.2979/NWS.2004.16.1.172

Jimoh, S. A. (1995). Ethical Issues in Research. In S. A. Jimoh (Ed.) Research Methodology in Education: an interdisciplinary approach (pp. 75-85). Unilorin: Publications Committee.

Kariuki, N. (2000). The challenges of financing research in institutions of higher education in Africa. Association of African Universities Conference on: Sustainable Development in Africa: The role of Higher Education. Retrieved from http://gc.aau.org/papers/ngotho_wa_kariuki_full20.pdf

Kellough, J. E., \& Pitts, D. W. (2005). Who Contributes to Public Administration Review? Examining the Characteristics of Authors Who Submit Manuscripts to the Journal. Public Administration Review, 65, 3-7. http://dx.doi.org/10.1111/j.1540-6210.2005.00425.x

Kraemer, K. L., \& Perry, J. L. (1989). Institutional requirements for academic research in public administration. Public Administration Review, 49(1), 9-16. http://dx.doi.org/10.2307/977224

Lazear, E. P. (1998). Personnel economics for managers. New York, NY: Wiley.

Lee, J. J., \& Rhoads, R. A. (2004). Faculty entrepreneurialism and the challenge to undergraduate education at research universities. Research in Higher Education, 45, 739-760. http://dx.doi.org/10.1023/B:RIHE.0000044229.70457.ca

Lewis, J. M., Ross, S., \& Holden, T. (2012). The how and why of academic collaboration: 
disciplinary differences and policy implications. Higher education, 64, 693-708. http://dx.doi.org/10.1007/s10734-012-9521-8

Lucas, C. J. (2006). American Higher Education: A History. Palgrave Macmillan, New York, NY.

Manyika, S., \& Szanton, D. L. (2001). PhD Programs in African Universities: Current Status and future Prospects. A Report to the Rockefeller Foundation. Berkley: University of California, Berkley.

Maunde, R. (2003). African Higher Education: An international reference handbook (pp. 636-648). Indiana University Press.

Ministry of Higher and Tertiary Education. (2010). Baseline study on the status of human capital development and training institutions in Zimbabwe. Machawira, M.S. (ed.)

Moses, I. (1986). Promotion of academic staff: Reward and incentive. Higher Education, 15, 135-149. http://dx.doi.org/10.1007/BF00138097

Majoni, C. (2014). Challenges Facing University Education in Zimbabwe. Greener Journal of Education and Training Studies, 2(1), 20-24.

Mutula, S. M. (2009). Challenges of Postgraduate Research: Global Context, African Perspectives. Key Note Address Delivered at the University of Zululand, $10^{\text {th }}$ DLIS Annual Conference.

Mwamwenda, T. S. (1994). Academics Stance on the slogan "Publish or Perish." Assessment and Evaluation in Higher Education, 19(2), 99-108. http://dx.doi.org/10.1080/0260293940190203

Odhiambo, A. (2004). Africa's 'brain gain' whose shibboleth? University of Michigan Library passages. Retrieved from http:hdl.handle.net/2027/spo.4761530.0009.004.

Oladunni, M. O. (1998). Dissemination of Research findings, implications for secondary school. Journal of Education Research and Evaluation No. 2.

Olsen, D., Maple, S. A., \& Stage, F. K. (1995). Women and minority faculty job satisfaction: Professional role interests, professional satisfactions, and institutional fit. Journal of Higher Education, 66(3), 267-293. http://dx.doi.org/10.2307/2943892

Oyewole, O. (2009). Introductory viewpoint Research and Information Technology Connectivity - Opportunities for Innovation and Issues for Africa. Paris: UNESCO.

Pellino, G. R., Boberg, A. L., Blackburn, R. T., \& O’Connell, C. (1981). Planning and evaluating a growth program for faculty. Monograph series No. 14 Ann Arbor, MI: Center for the Study of Higher Education, School of Education, University of Michigan.

Plucker, F. E. (1988). Institutional factors that motivate research activity in research universities. Paper presented at the annual meeting of the Association for the Study of Higher Education, St. Louis, MO. 
Sabharwal, M. (2012). Productivity and Leadership Patterns of Female Faculty Members in Public Administration. Journal of Public Affairs Education. 19(1), 73-96.

Sanyal, B. C., \& Varghese, N. V. (2006). Research Capacity in Higher Education Sectorin Developing Countries. UNESCO: Paris.

Sawyerr, A. (2004). African Universities and the Challenge of Research Capacity Development. JHEA/RESA, 2(1), 211-240.

Sax, L. J., Hagedorn, S., Arredondo, M., \& Dicrisi, F. A., III. (2002). Faculty research productivity: Exploring the role of gender and family-related factors. Research in Higher Education, 43(4), 423-446. http://dx.doi.org/10.1023/A:1015575616285

Serow, R. C. (2000). Research and teaching at a research university. Higher Education, 40, 449-463. http://dx.doi.org/10.1023/A:1004154512833

Serow, R. C., \& Demry, J. (1999). Faculty perspectives on teaching at a research university. Paper presented at the annual meeting of the Association for the Study of Higher Education, San Antonio, TX.

Share, F. (2010). Zimbabwe tops Africa literacy rate. Retrieved from http://www.newzimbabwe.com/news-2840-zim+tops+africa++rate/news.aspx.

Smith, P. (1990). Killing the Spirit: Higher Education in America. Viking Penguin, New York, NY.

Stallings, R. A., \& Ferris, J. M. (1988). Structure and the dilemma of organizational change. Teachers College Record, 103(6), 1081-1101.

Tien, F. F., \& Blackburn, R. T. (1996). Faculty rank system, research: What motivates university faculty members to do research?: Tenure-track faculty in research extensive universities. Journal of the Professoriate, 2(1), 75-99.

University World News, Africa Edition. (2010). Zimbabwe: University's funds looted, intakes $\begin{array}{llll}\text { frozen. } & \text { February } & 2010 . & \text { Retrieved }\end{array}$ http://www.universityworldnews.com/article.php?story=20100226132512916

Wong, M. P. \& Tierney, W. G. (2001). Reforming faculty work: Culture, structure and the dilemma of organizational change. Teachers College Record, 103(6), 1081-1101. http://dx.doi.org/10.1111/0161-4681.00143

Wright, B. E., Manigault, L. J., \& Black, T. R. (2004). Quantitative research measurement in public administration: An assessment of journal publications. Administration and Society, 35(6), 747-764. http://dx.doi.org/10.1177/0095399703257266

Zakri, A. H. (2006). Research Universities in the 21st century: Global Challenges and Local Implications. Paper presented at the UNESCO Forum on Higher Education, Research and Knowledge: Colloquium on Research and Higher Education Policy, November 29-December 1, 2006, Paris. 


\section{Macrothink}

International Research in Education

ISSN 2327-5499 2015, Vol. 3, No. 1

Zeleza, P. T., \& Olukoshi, A. (2004). African Universities in the Twenty First Century Liberalisation and Internationalization, 1. South Africa: UNISA Press.

Zimbabwe Council for Higher Education (ZIMCHE) (2013). Guidelines for staff appointment, tenure and promotion.

\section{Copyright Disclaimer}

Copyright reserved by the authors.

This article is an open-access article distributed under the terms and conditions of the Creative Commons Attribution license (http://creativecommons.org/licenses/by/3.0/). 